\title{
On the influence of lateral cells and local perforation of resonance liner samples on the accuracy of determining their acoustic characteristics in experimental studies
}

\author{
Oleg K ustov* and Igor K hramtsov \\ Perm National Research Polytechnic U niversity, 614990, Perm, Russia
}

\begin{abstract}
When determining the acoustic characteristics of a single-layer sample of a honeycomb liner by experiments in interferometers with normal wave incidence, a significant effect of incomplete lateral cells of the sample on acoustic characteristics was revealed. The experiments were carried out on two interferometers with channel diameters of 30 and $50 \mathrm{~mm}$ in the frequency range $500-3500 \mathrm{~Hz}$ at sound pressure levels of 120-155 dB. Based on the results of the experiments, an assessment was made of the effect on the acoustic characteristics of the percentage of perforation, which is the same both for one honeycomb cell and for the entire SAS sample. B ased on the results of the research, recommendations were made to improve the accuracy of obtaining the acoustic characteristics of samples of honeycomb liner when testing them in interferometers of normal wave incidence.
\end{abstract}

\section{Introduction}

In connection with the tightening of international standards for aircraft noise on the ground, it is necessary to constantly improve the means of reducing the noise of aircraft engines and to include in consideration an increasing number of possible factors affecting the efficiency of such means.

A s you know, in modern turbofan engines, due to the high degree of bypass, the dominant source is the fan [1, 2], and the main means of reducing the fan noise are resonant liner. Liner design is based on semi-empirical models [3-10], the main disadvantages of which include: 1) simplified mathematical formulations, which do not fully take into account physical effects (compressibility, viscosity, thermal conductivity, vortex formation), which are important from the point of view of an accurate description of SA S operation processes at high sound pressure levels typical of aircraft engine channels; 2 ) relatively large scatter of semiempirical coefficients used in the models (for example, the attached length of the resonator throat varies from 0.785 to 0.85 of the diameter of the perforation hole in different works [11-13], and in the presence of a tangential flow it varies even more [14]), which noticeably affects the accuracy of the description of the liner impedance; 3 ) the acoustic characteristics of only 1layer liner are predicted relatively acceptable.

\footnotetext{
*Corresponding author: KustovOU @ yandex.ru
} 
The first of these drawbacks can also be the reason that semi-empirical models weakly "catch" the influence of small deviations of the geometric parameters of the liner, due to the manufacturing technology, on the acoustic characteristics, which can be very strong, as field tests of liner samples show. For example, in [15, 16], strong deviations of the design values of the resonant frequency are noted due to an error of $0.1 \mathrm{~mm}$ in the main geometric parameters of the holes in the resonator cells. In addition, in semi-empirical models, the percentage of liner perforation is taken on a conditional area, although the model needs to be adjusted for a specific type of resonator and its surface (local) perforation area. In reality, the entire panel of the liner is perforated with the preservation of the perforation percentage, where the holes often fall on the walls of the honeycomb filler, on the joint seams, etc., thereby locally distorting the obtained acoustic characteristics [15].

This work continues the study of the influence on the acoustic characteristics of the features of the geometry of liner samples of different diameters, manufactured for testing in interferometers of normal incidence.

\section{Geometric parameters of resonance liner samples used in the experiments}

The experimental part of the work considers two sets of liner samples. These samples have the same "declared" geometric characteristics (perforation rate $7.6 \%$, height of the honeycomb filler, thickness of the perforated plate and hole diameter). However, each sample has small differences (different number of holes per area of each sample, different volume of side cells and the number of perforation holes in them, etc.), which are usually not taken into account when predicting acoustic characteristics.

Fig. 1 shows the first set. The first two samples have different diameters, and the holes are located so that they do not fall on the walls of the honeycomb cells. The percentage of perforation for the area of each sample and for the area of each individual cell (including the lateral one) is nearly the same (Table 1). Samples of this design were made using additive technologies.

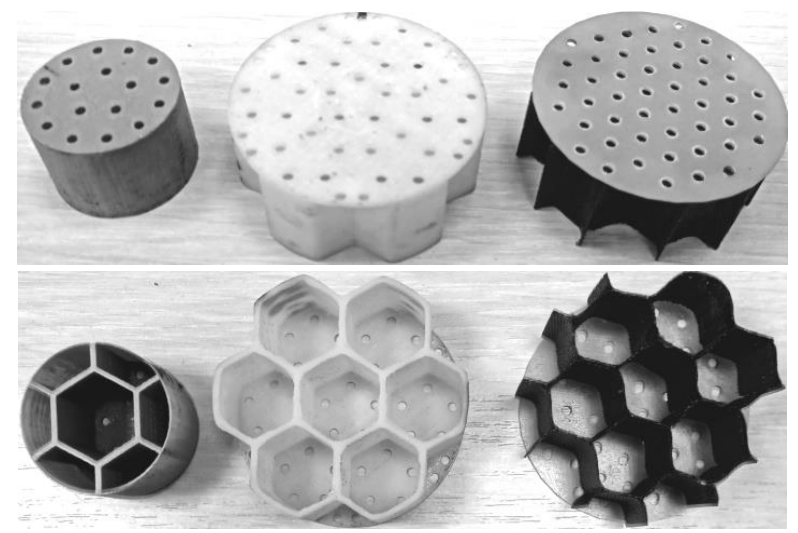

Fig. 1. Test liner samples with preservation of the perforation percentage over the entire area 
Table 1. Geometrical parameters of liner test samples, first set.

\begin{tabular}{|c|c|c|c|c|c|c|c|}
\hline Samples & $\begin{array}{c}\text { Sample } \\
\text { diameter } \\
(\mathrm{mm})\end{array}$ & $\begin{array}{c}\text { Perforation } \\
\text { percentage } \\
(\%)\end{array}$ & $\begin{array}{c}\text { Number } \\
\text { of holes } \\
\text { (pcs) }\end{array}$ & $\begin{array}{c}\text { Cell } \\
\text { resonator } \\
\text { height } \\
(\mathrm{mm})\end{array}$ & $\begin{array}{c}\text { Perforated } \\
\text { plate } \\
\text { thickness } \\
(\mathrm{mm})\end{array}$ & $\begin{array}{c}\text { Hole } \\
\text { diameter } \\
(\mathrm{mm})\end{array}$ & $\begin{array}{c}\text { M anufacturing } \\
\text { method }\end{array}$ \\
\hline H20D30 & 30 & 7.55 & 17 & 20 & 1 & 2 & 3 D printing \\
\hline H20D50 & 50 & 7.52 & 47 & 20 & 1 & 2 & 3D printing \\
\hline H20D50сб & 50 & 7.68 & 48 & 20 & 1 & 2 & Fabricated \\
\hline
\end{tabular}

A ccording to industrial technology, the perforation plate is manufactured with a constant pitch between holes, providing the design value of the perforation percentage only for the entire plate area. However, if you cut out round samples from it, then a different number of holes will get into samples, which will also lead to small deviations from the declared perforation, which can be seen in Table 1 for the third sample, which is assembled from a perforated plate (holes are evenly distributed over the entire area of the plate with $6 \mathrm{~mm}$ pitch) and standard fiberglass $20 \mathrm{~mm}$ high with a cell side of $9 \mathrm{~mm}$. In addition, in such a sample, some holes fall on the ribs of the resonators.

To investigate the effect of side cells on acoustic performance, in the second set of samples (Fig. 2) the holes in the side cells were removed, which slightly changed the "claimed" perforation rate of $7.6 \%$. M ore details are presented in table 2.

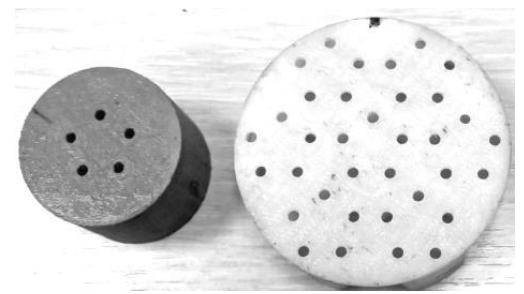

Fig. 2. Liner samples with preservation of the perforation percentage for the cells

Table 2. Geometrical parameters of SAS test samples, second set

\begin{tabular}{|c|c|c|c|c|c|c|c|}
\hline Samples & $\begin{array}{c}\text { Sample } \\
\text { diameter } \\
(\mathrm{mm})\end{array}$ & $\begin{array}{c}\text { Perforation } \\
\text { persentage } \\
(\%)\end{array}$ & $\begin{array}{c}\text { Number } \\
\text { of holes } \\
(\mathrm{pcs})\end{array}$ & $\begin{array}{c}\text { Cell } \\
\text { resonator } \\
\text { height } \\
(\mathrm{mm})\end{array}$ & $\begin{array}{c}\text { Perforated } \\
\text { plate } \\
\text { thickness } \\
(\mathrm{mm})\end{array}$ & $\begin{array}{c}\text { Hole } \\
\text { diameter } \\
(\mathrm{mm})\end{array}$ & $\begin{array}{c}\text { M anufacturing } \\
\text { method }\end{array}$ \\
\hline H20D30 & 30 & 7.46 & 5 & 20 & 1 & 2 & 3D printing \\
\hline H20D50 & 50 & 7.46 & 35 & 20 & 1 & 2 & 3D printing \\
\hline
\end{tabular}

The geometry of the test samples of resonant liner was chosen so that the natural frequency of the samples fell within the operating frequency range of the experimental installations. At the same time, the main geometric parameters (height, perforation degree, thickness of the perforated sheet) had to be close to the full-scale single-layer liner panels used on modern aircraft engines.

Due to the disadvantages of semiempirical models indicated in the introduction, the prediction of the acoustic characteristics of the selected samples was carried out on the basis of numerical modeling of physical processes in a normal incidence interferometer with a liner sample, the features of which are briefly indicated in the next section. The technique used has proven itself well, including for resonant multilayer liner [17-19]. 


\section{Features of experimental study and numerical simulation}

The diameter of the designed samples of 30 and $50 \mathrm{~mm}$ was due to the diameter of the channel cross-sections of interferometers with normal incidence used in experimental studies [18]. The interferometer is a cylindrical tube, at one end of which a liner sample is located, and at the other end there is a speaker that irradiates the sample with an acoustic signal at sound pressure levels of 120-155 dB. The operating frequency ranges of interferometers with channel diameters of 30 and $50 \mathrm{~mm}$ for the use of the 2-microphone transfer function method [19] are 500-6400 and 400-4200 Hz, respectively. Investigations of liner samples are carried out in the frequency range of $500-3500 \mathrm{~Hz}$.

Numerical modeling of acoustic processes was based on the direct solution of the NavierStokes (DNS) equations taking into account the compressibility in the ANSYS Fluent software package [20]. The geometry of the interferometer channel and the honeycomb resonator of the liner samples was used. The geometry of the liner sample corresponded to the design geometric parameters presented in Tables 1 and 2 . The modeling technique is described in more detail in [17-19]. In this study, the formulations of the calculation are considered when an acoustic wave is incident on only one honeycomb resonator in a channel with a diameter of $16.4,30$ and $50 \mathrm{~mm}$ (Fig. 3).

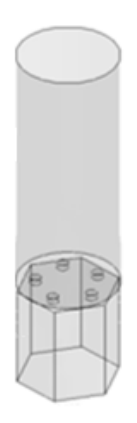

a)

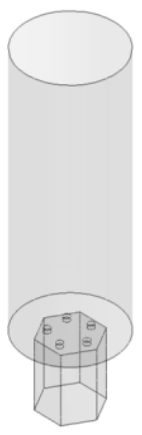

b)

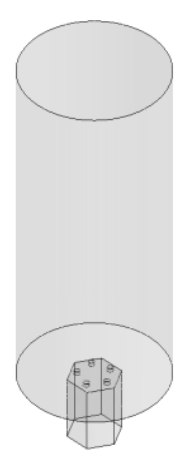

c)

Fig. 3. Geometric models of the computational domain:

a) channel $d=16.4 \mathrm{~mm}$; b) channel $d=30 \mathrm{~mm}$; c) channel $d=50 \mathrm{~mm}$.

\section{Comparison of the results of numerical simulation and experiment}

The results of comparing the acoustic characteristics of the liner samples obtained in experiments for $\varnothing 50 \mathrm{~mm}$ are presented in Figures 4-6. Up to a sound pressure level (SPL) of $140 \mathrm{~dB}$, samples behave completely differently, but at high SPLs, samples with a large number of holes and different perforation spacing have similar acoustic characteristics. This is due to strong nonlinear effects near the holes, when fine tuning of the geometric parameters of the resonator loses its significance. The central honeycomb with local perforation (blue curve in Fig. 4-6), begins to lose the efficiency of sound absorption and the value of the attached length due to high velocities in the throat of each hole while moving aw ay from the linear modes. The semi-empirical model did not allow to estimate this effect. The central honeycomb without lateral half-cells (local perforation) $\varnothing 30 \mathrm{~mm}$, and with lateral half-cells for the interferometer 30, has a similar dependence.

Liner samples with preservation of the perforation percentage for cells without lateral hemispheres (Fig. 2, Table 2) also have different acoustic characteristics. The influence of 
the diameter of the interferometer channel is clearly expressed here. Detailed characteristics of samples at SPL $130 \mathrm{~dB}$ are shown in Fig. 7.
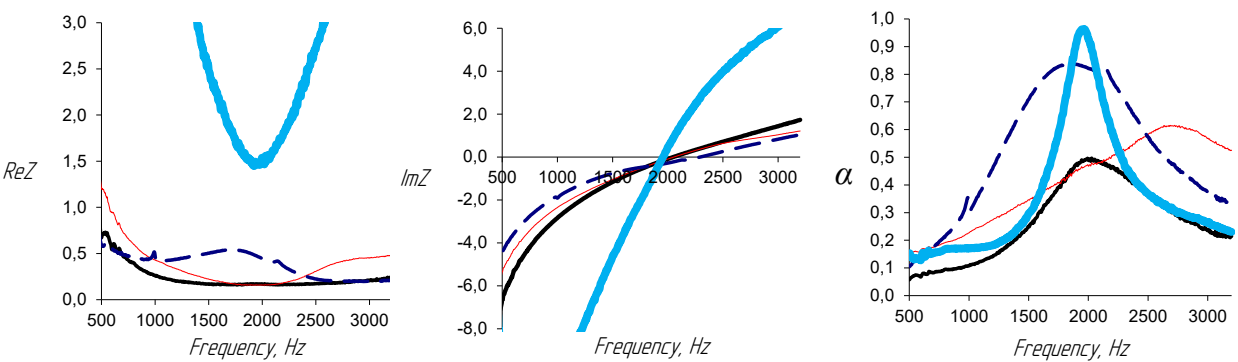

Fig. 4. A coustic characteristics of $\varnothing 50$ test samples at $130 \mathrm{~dB}$ SPL:

Central cell (1 pc.);

- All full cells (7 pcs.);

Full cells + side half-cells;

- - - - - Solid perforation
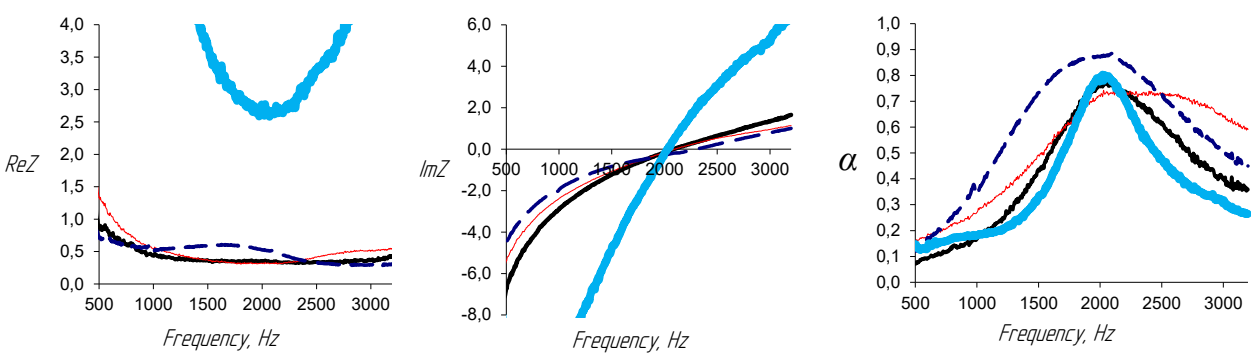

Fig. 5. A coustic characteristics of Ø50 test samples at $140 \mathrm{~dB}$ SPL:
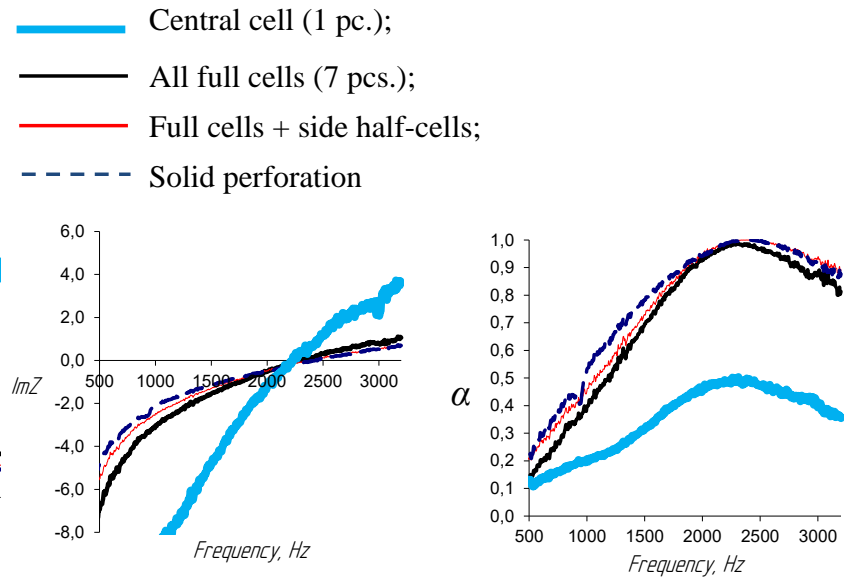

Fig. 6. A coustic characteristics of $\varnothing 50$ test samples at $155 \mathrm{~dB}$ SPL:

Central cell (1 pc.);

- All full cells (7 pcs.);

Full cells + side half-cells;

- - - - - Solid perforation 

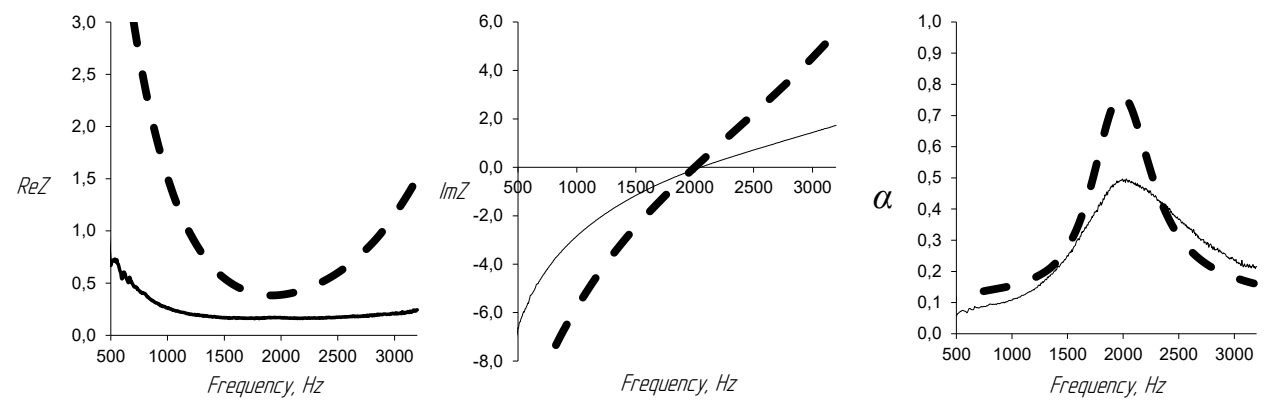

Fig. 7. A coustic characteristics of $\varnothing 30$ and $\varnothing 50$ test samples with preservation of perforation percentage for cells at SPL $130 \mathrm{~dB}$ :

- - Interferometer Ø30, cell (1 pc.); Interferometer Ø50, cell (7 pcs.)

Figure 8 shows the acoustic characteristics of the honeycomb resonator, obtained on the basis of numerical simulation in the formulations presented in Fig. 3.
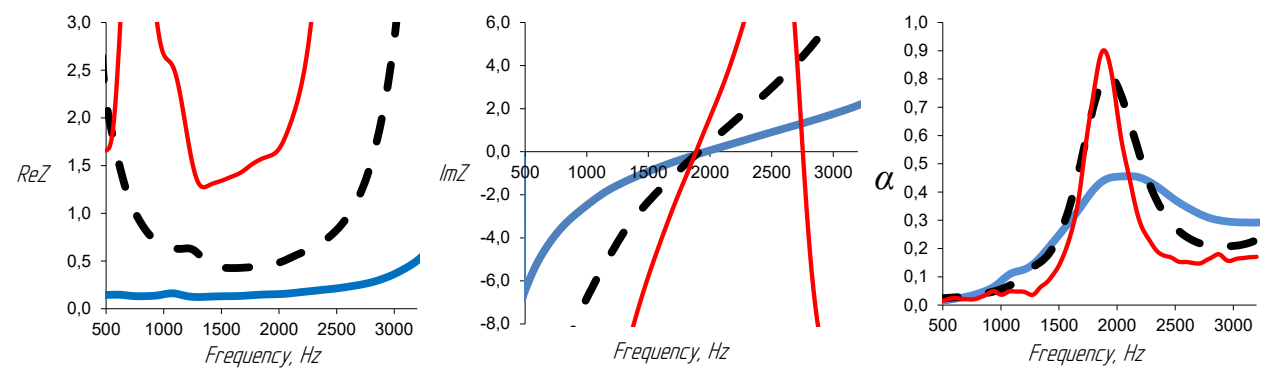

Fig. 8. A coustic characteristics obtained from numerical simulations at $130 \mathrm{~dB} S P L$ :

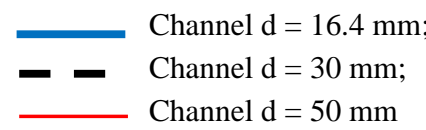

From the analysis of the data obtained, it can be concluded that with an increase in SPL, the differences decrease in the values of impedances, sound absorption coefficients and resonance frequencies of samples with lateral half-cells and samples with holes that fall on the walls of the honeycomb resonator. Therefore, for a qualitative assessment of the liner, high SPL levels are required on experimental installations, more than $145 \mathrm{~dB}$. When assessing the acoustic characteristics of large-sized liner using measurements with a portable interferometer [23], in order to reduce the scatter of acoustic characteristics and the number of measurement points, tests should al so be carried out only at high sound pressure levels.

It is worth noting the samples with lateral half-cells. Such a sample has two sets of resonator cells of different volumes - full and truncated cells, which makes significant adjustments to the real part and the natural frequency of the sample as a whole. The overall perforation percentage of the entire sample is not preserved and the central cell dominates over the lateral ones. The influence of incomplete side cells of a sample of a honeycomb sound-absorbing structure on the accuracy of acoustic characteristics for other samples of liner was partially considered in the article [17].

In the results of numerical simulation and experimental data, there is a good agreement between the values of the resonance frequency and characteristics in general. This is important for confirming the operability of the applied numerical modeling technique in predicting the acoustic characteristics of the liner used for facing the channels of an aircraft engine. 


\section{Conclusion}

As a result of the studies, it can be concluded that for a more accurate understanding of the acoustic characteristics of the liner based on measurements in interferometers, it is necessary to pay special attention to the preparation of liner samples. It is important to maintain local perforation for each cell in the sample. It is advisable not to use the lateral half-cells in the liner samples when testing them in interferometers, since their presence can significantly distort the obtained acoustic characteristics. When verifying the results of numerical modeling based on experimental data, it is important to use samples made with the smallest possible size errors. Also, according to the research results, it can be concluded that, the method for determining the acoustic characteristics based on numerical modeling is efficient and can be used in the future in the development of new resonant type liner.

This work was supported by UEC JSC.

\section{References}

1. V.F. Kopiev, A.G. M unin, N.N. Ostrikov, Proceedings of TsA GI 2739, 3-13 (2014).

2. L. L eylekian, M. L ebrun, P. Lempereur, Journal A erospace Lab 7, (2014).

3. U. Ingard, J ournal of the A coustical Society of A merica 44(4), 1155-1156 (1968).

4. T.H. M elling, Journal of Sound and V ibration 29(1), 1-65 (1973).

5. A.W. Guess, Journal of Sound and V ibration 40(1), 119-137 (1975).

6. A.S. Hersh, B.E. W alker, and J.W. Celano, A IA A Paper 1825 (1999).

7. H. Boden, AIAA Paper 2005-2896 (2005).

8. A.F. Sobolev, A coustical Physics 53(6), $762-771$ (2007).

9. Jia Y u, M arta Ruiz, Hwa Wan K wan, AIA A Paper 2930 (2008).

10. A.I. Komkin, M.A. M ironov, A.I. Bykov, A coustic journal 63(4), 356-363 (2017).

11. U. Ingard, J ournal of the A coustical Society of A merica 25(6), 1037-1061 (1953).

12. M.R. Stinson, E.A. Shaw J ournal of the A coustical Society of A merica 77(6), 2039-2042 (1985).

13. T. Elnady and H. Boden, A IA A Paper 3304 (2003).

14. R.E. Motsinger, R.E. K raft, A eroacoustics of flight vehicles. Theory and practice. A coustical Society of A merica, (1995).

15. O.Y u. K ustov, Scientific and technical bulletin of the V olga region 8, 21-23 (2018).

16. O.Y u. Kustov, I.V. Khramtsov, R.V. Bulbovich, Bulletin of Samara University. A erospace engineering, technology and mechanical engineering 18(1), 67-77 (2019).

17. I.V. K hramtsov, O.Y u. K ustov, V.V. Palchikovskiy, A kustika 32, 182-188 (2019).

18. I.V. K hramtsov, O.Y u. K ustov, V.V. Palchikovskiy, A kustika 34, 32-36 (2019).

19. E.S. Fedotov, I.V. Khramtsov, O.Y U. Kustov, AIP Conference Proceedings 1770(030120), (2016).

20. O.Y u. Kustov, V.V. Palchikovskiy, I.A. Korin, I.E. Cherepanov, I.V. Khramtsov, Bulletin of the Perm National Research Polytechnic U niversity. A erospace engineering 51, 62-73 (2017).

21. ISO 10534-2:1998, part 2: Transfer-function method (1998).

22. Ansys User's guide, A nsys Release 17.0. A nsys Inc. (2016).

23. I.A. Korin, R.V. Bulbovich, V.V. Palchikovskiy, O.Y u. Kustov, Izv. Universities. $A$ viation technology 1, 83-87 (2020). 